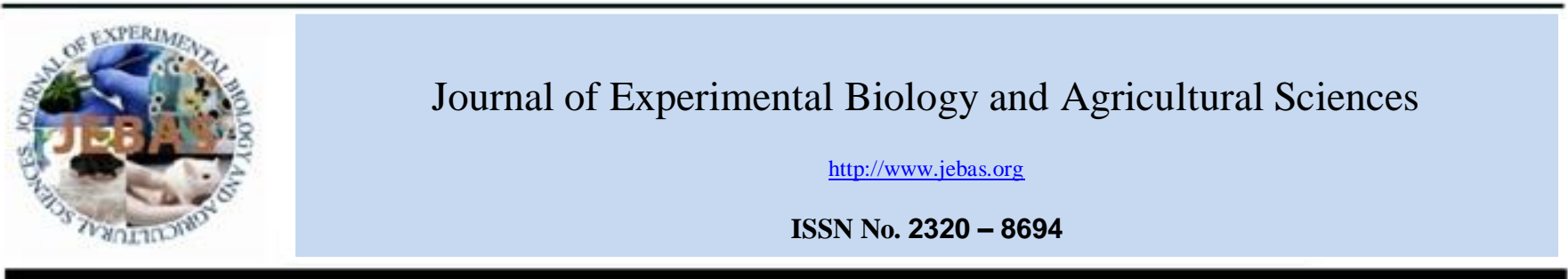

\title{
STRATEGY OF MANAGING GROWTH OF AGRICULTURAL PRODUCTION IN RUSSIA
}

\section{Marina Yegorovna Anokhina}

Ph.D. in Economics, Senior lecturer, Department of organizational and managerial innovations,

Plekhanov Russian University of Economics, 36, Stremyanny lane, Moscow, 117997 Russian Federation

Received - July 26, 2017; Revision - November 13, 2017; Accepted - December 03, 2017

Available Online - December 27, 2017

DOI: http://dx.doi.org/10.18006/2017.5(6).793.805

\section{KEYWORDS \\ Russian AIC \\ Economic growth \\ Trends \\ Agricultural production \\ Strategic initiatives}

\begin{abstract}
The aim of the study was to determine the dependence of the parameters of economic growth agroindustrial complex (AIC) from identifiable groups of factors. In this article author presents the study of the processes of economic dynamics of agricultural production in Russia. The basis for the development of the author's concept of management of economic growth in agro-industrial complex was economic growth theory, the theory of cyclical development of the economy and the theory of industrial organization. The concept focuses on factors, determinators and conditions of economic growth and their causal relationships, the latter being additional driving force of economic dynamics of an industrial complex. Results of study represent the Russia's AIC economic growth in last few decades. Results of this study based on the statistical data for the past 10 years and the economic-mathematical modeling. From the results, it is revealed that under current agricultural policy it is quite difficult to ensure the dynamic development of the industrial complex in accordance with the existing agricultural potential of the country. As part of the author's concept of the AIC economic growth management, the strategic initiatives have been developed, the implementation of which would allow to consolidate the positive trend in the production of agricultural products and to create conditions for a new quality of Russian agricultural sector growth in the long term.
\end{abstract}

* Corresponding author

E-mail: marina_anokhina@mail.ru, Anokhina.ME@rea.ru (Marina Yegorovna Anokhina)

Peer review under responsibility of Journal of Experimental Biology and Agricultural Sciences.

Production and Hosting by Horizon Publisher India [HPI] (http://www.horizonpublisherindia.in/).

All rights reserved.
All the article published by Journal of Experimental Biology and Agricultural Sciences is licensed under a Creative Commons Attribution-NonCommercial 4.0 International License Based on a work at www.jebas.org.

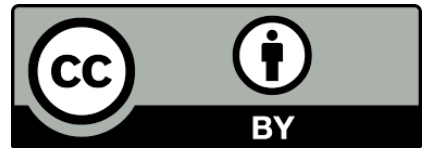




\section{Introduction}

The problem of economic growth in Russia is especially urgent due to the complexity of the economic and political situation in the world. The stability and dynamism of the national economic system helps to mitigate the social tensions and helps to preserve the sovereignty of the state and revive the country's former power on a brand new qualitative level. The successful solution of the problems of economic growth is determined by the scientific validity and viability of the methodological concepts underlying it, since in the modern conditions the price of errors is extremely large and may entail the disastrous consequences.

Various evidences developed from the historical experience of economically developed countries and individual economic achievements of Russia suggest that the need of economic growth must be manage. The need to manage the economic growth of the national economic system is determined, on the one hand, by the fact that the market mechanisms are not developed enough to promote the growth potential (primarily through structural adjustment and long-term investments). On the other hand, the experience of countries with developed market mechanisms clearly demonstrates the active influence of the state at the economic processes with a view to adjusting them in the direction of solving problems of effective social and economic dynamics. Such an impact is nothing more than managing the economic growth of the national economic system at various organizational levels. In the conditions of political and economic instability, this problem becomes especially urgent for the agro-industrial complex of the country.

The agrarian development of Russia in the context of managing the economic growth of the agro-industrial complex is quite controversial at this stage. It does not differ in the systematic approach and does not provide the adequate economic dynamics in accordance with the available agro-industrial potential. This is confirmed by the macroeconomic ratios, which pose threat to the national interests and cause economic threat to the country. Russia possesses $9 \%$ of the world's productive arable land, $20 \%$ of the world's fresh water reserves, produces $8.5 \%$ of the world's mineral fertilizers, but cannot satisfy its food products needs and must import food to the amount of $\$ 24.9$ billion.

Hence, the aim of the study was to develop a theoretical concept for managing the economic growth of the agro-industrial complex and to formulate an algorithm for its use to ensure high economic dynamics of the industry complex, considering the country's agricultural potential. After analyzing the theory of economic growth, we may note that in the economic theory there are different concepts of economic dynamics, which include the theory of economic growth, the theory of sustainable growth, the theory of sustainable economic development. We are guided by the proposed essential characteristic of the economic growth which includes aspects of growth, development and sustainable functioning. This position is based on the current economic situation, characterized by a high level of dynamism and complexity of economic, political, social, and environmental processes. In such conditions, sustainability and development are the necessary pre-requisites for the economic growth and development. In its content, the economy at any organizational level is the economy of the development, functioning of which can be accompanied by the progress and regress. However, the need to continuously meet mass needs determines the need for its constant development in chosen direction as requirements to the economy, which is ensured by its stable character. The economic growth without creating conditions for managing the future through the sustainability of the development process is doomed to failure, and it may not be deemed a growth in its essence. Therefore, the author does not determine the unambiguous and precise boundary between this concept and the concepts of sustainable economic growth and economic development when studying the state of scientific development of the concept of economic growth. The integration of concepts is based on the introduction of the "generating economic growth" concept, which includes the notions of "sustainable economic growth" and "sustainable economic development".

Considering the specifics of the industry complex as a subject to the economic growth management and the cyclical nature of the process of economic dynamics, three groups of theories were selected as the methodological basis for the development of the theoretical concept of the economic growth of the agro-industrial complex: economic growth theory, cyclic dynamics theory and the theory of industrial markets. At the junction of these three groups of theories, the theoretical concept of the economic growth of specific branches may be scientifically grounded (Figure 1). The author's concept emphasizes the structuring of the economic growth factors (the identification of factors, determinants and conditions of economic dynamics) and the establishment of cause and effect relationships between them. We'll consider the provisions of the main ones, which allowed substantiating the author's approach.

The representatives of the neo-Keynesian direction, such as Domar (1957), Harrod (1973), Hamberg (1971), Robinson (1962) showed the special role of demand for investments in achieving the dynamic equilibrium.

The studies on the influence of individual growth factors on economic dynamics characterize the content of the neoclassical approach (Solow, 1956; Denison, 1967; Phelps, 1962; Koopmans, 1965; Cass, 1965; Ramsey, 1928; Diamond, 1965; Arrow, 1962). Continuing the neoclassical tradition and supplementing it with a study of intangible capital, Shell (1967) developed a model based 


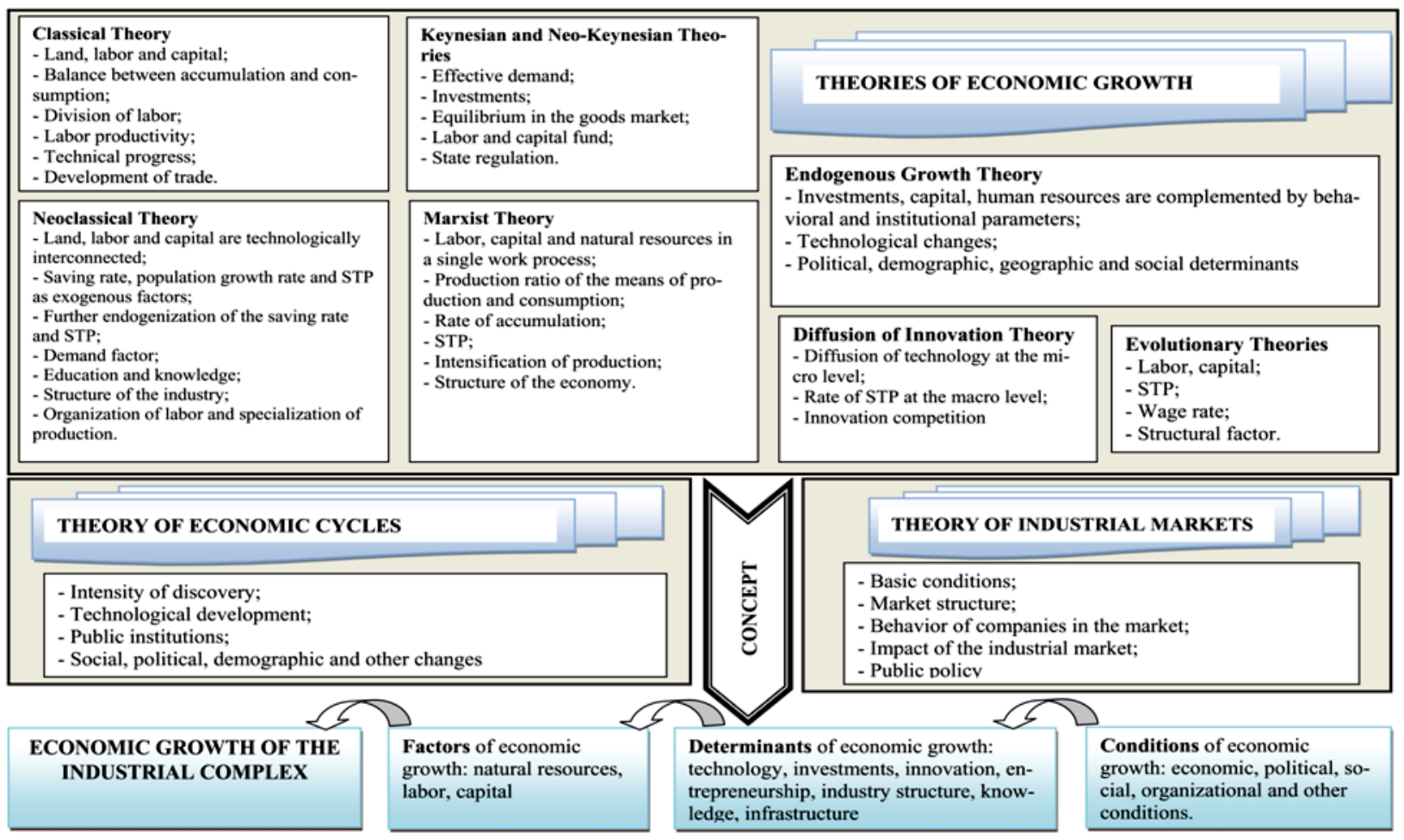

Figure 1. Theoretical concept of economic growth of the industrial complex

on the methodology of the two-sector analysis by Uzawa (1963) (division of the economy into three sectors: production, innovations and invention), identified knowledge as a separate, specific production factor and determined that its accumulation was directly related to the rate of economic growth.

The modern practice of research in the field of economic growth is characterized by two main directions: endogenization of the growth factors and a deeper study of the influence of scientific and technical progress on economic dynamics. The most famous evolutionary model of economic growth is the Nelson-Wintor model (2002).

Theoretical models of endogenous growth are focused on the search for behavioral and institutional parameters that determine the sustainability of long-term economic growth. This refers to a number of parameters, such as the level of education (Barro \& Lee, 1994), various aspects of state policy (Levine \& Renelt, 1992; Barro, 1997), trade policy parameters (Levine \& Renelt, 1992; Romer, 1993).

The authors of the model of economic growth based on systemic re-industrialization (Bodrunov, 2013; Buzgalin, 2014) consider modernization of the technological base of the economy, structural policy change, introduction of innovative economic elements, significant effective investments in human capital as driving force for sustainable economic growth.

The structural and technological approach is used in the methodology of advanced development (Glazyev \& Fetisov, 2013), the methodology of qualitative economic dynamics (Voronin et al., 2004), the methodology of structural shifts (Krasilnikov, 2005; Sukharev, 2013; Yakovets, 2004), the methodology of unity of neo industrialization and vertical integration (Gubanov, 2012).

In the context of economic growth factors, one of the interesting studies is about the relationship between economic growth and inequality (Piketty, 2016). A "unified field theory" is proposed for inequality, which integrates economic growth into a single structure, the distribution of income between capital and labor, the distribution of wealth and income among the individuals.

In general, the theories of economic growth presented are focused on the search for factors, determining the nature and power of their influence on economic dynamics. With many growth factors and their diversity, it should be noted that all theories considered natural resources, labor and capital as factors of growth in varying degrees, in different forms and with different parameters. The other part of the factors is more numerous. Based on their 
quantitative and qualitative composition, it depended on the objectives and base of the research, used methodology and the available tools for theoretical and empirical search. These factors included scientific and technological progress, technology, investment, innovation, structural policy, training, etc. This group of factors is mobile in terms of its composition and content due to many variations, rate of economic changes. It is confirmed by the presented results of assessing the evolutionary development of economic growth theory. The economic theory in the field of scientific justification of economic growth with a huge number of developments and concepts clearly contradicts with the considerable accumulation of theoretical facts and the limited methodological approaches that allow solve the problems associated with the economic dynamics.

In terms of methodology, the theory of economic growth and the theory of economic cyclicality are closely interrelated since the growth is a function of the economic cycle. The cyclicality in relation to the economic system is a process caused by a violation of equilibrium in it at certain intervals and accompanied with a significant expansion or contraction of business activity in most sectors of the economy. When developing the theoretical concept of economic growth of industrial complexes, the relevance of theories of economic cyclicality is significant, because it is this direction of economic theory that reveals the most important conditions under which stability, balance and irreversibility of progressive changes in the economic system are ensured.

The studies aimed at identifying the laws of long-term development, based on scientific and technological progress, are rather widely represented in the modern science. The examples include works like Freeman \& Louca (2001), Ayres (2006), Grubler (1998), which reveal and substantiate the processes of economic dynamics caused by innovative activity, structural shifts in the economic system, and the emergence of a new technological order.

A different vision of the causes of the imbalance in the economic system as a methodological basis of economic cyclical theories makes it possible to emphasize a number of directions in this field of research, which include the over accumulation theory in the capital sector (Forrester, 2006), the social concept (Freeman, 1982), the price theory (Rostow, 1980), Keynesian and neoKeynesian theories (Hansen, 1951; Fisher, 1933; Hicks, 1992). The aspects of practical application of the cyclic development theories presented by Hirooka (2006) and Akayev et al. (2012) are connected with the calculations and diagnostics of the economic growth, which is based on the nonlinear cyclic function.

The considered theories of economic cyclicality within the context of the developed concept of economic growth of industrial complexes allow us to state that cyclical iterations in the state of the economic system are objective, but manageable. The managerial capabilities are implemented based on the conditions under which the zigzag-shaped dynamics of the state of the economy will generate an upward wave of the aggregate social product with targeted quantitative and qualitative parameters. As such conditions in the theories of economic cyclicality, the intensity of introduction of scientific and technical progress, the state of the system of public institutions, the level of the monetary system, the structural and technological shifts, and the social and demographic changes are justified.

In economic theory, the study of the economic growth of the industry or industrial complexes as a special direction in has not been represented. In order to take into account industry specific features in the formation of the concept of the economic growth of the industrial complex as a structural part of the national economic system, the relations between the participants are based on the principles of economic benefit, operational expediency, social significance and are generally determined by the needs of the consumer. The theories of the industry markets and their content have been examined. As the most important in this group of theories, the concepts of analysis of sectoral markets and the system of state regulation of the sectoral structure are defined.

The main provisions of the theory of industrial markets are developed by scientists on the basis of historical experience using market mechanisms and the availability of an appropriate research base in the form of industry markets. This direction of research has been named "industrial organization". In 1950s, the scientists of Harvard School Mason (1949) and Bain (1959) have formed the methodology "Structure-Conduct-Performance" - SCP, which reflected the content of the market mechanism of relations between the producer and the consumer and was built on the basis of a systematic approach. In the later works of Scherer \& Ross (1990), Heather (2004), Viscusi et al. (2000), the concept of SCP was supplemented by the blocks of the "Basic conditions" and "State policy" with the justification of the feedbacks between the elements.

One of the important directions of theoretical and empirical research within the studies by the Chicago school is the functioning and effectiveness of quasi-monopoly markets, the features of which are described by the theory of transaction costs and the theory of quasi-competitive markets (Demsetz, 1974; Baumol et al., 1982).

Based on the study of theoretical and methodological materials in regards to economic dynamics of industrial complexes, taking into account the theoretical conception of the economic growth, the author has determined that the economic growth of the agroindustrial complex as a process of social and economic dynamics of the volume and content of the social product being created will 
take place in the presence of certain factors and conditions that ensure the quantitative, qualitative and reproductive changes within the economic system. In the presented concept, there is an emphasis not only on the factors and conditions of economic growth, but also on the causal relationship between them, which act as an additional driving force for the economic dynamics of the agro-industrial complex. Within this context, the factor and the conditions of economic growth should be clearly differentiated. The factor of economic growth is the primary cause of changes in the volume and content of the social product and forms the basis for the social and economic development of the industrial complex as an economic system. The conditions of economic growth should be viewed as an environment that determines the opportunities for growth factors and, as a consequence, affects the nature and content of the economic dynamics of the industry complex.

With many growth factors and their diversity, given the different level of significance and the relationships between them, which often have the cause-effect characteristics, we find it possible to differentiate the factors according to these criteria by identifying a group of basic and deterministic growth factors. The basic factors directly affect the economic dynamics. Without their presence, the growth as such is not possible. The determinants that influence the economic growth indirectly ensure the reproduction of basic growth factors and more efficient use of them. The more determinants will be available with an adequate content and effective ratio, the wider will be the opportunities to activate growth factors to ensure quantitative, qualitative and reproductive dynamics of the economic system.

\section{Materials and Methods}

The economic growth of AIC considering the specifics and social importance of the agricultural sector are results in the increase of value of the main types of agricultural products per capita, the positive dynamics of their reproduction and the creation of conditions for sustainable development of the agri-food business in the long term (Anokhina, 2016).

The economic growth in agribusiness is primarily determined by volumes, conditions and manner of use of the natural biological resources, labor and capital. These parameters of economic growth, in fact, are factors of agricultural production growth. However, the possibility to ensure economic growth only due to growth factors is limited, which assumes the creation of additional resources for their effective and rational use. These sources act as the determinant for the growth regulators. With regard to the AIC within the context of a modern economic situation, the following determinants of growth factors should be noted: investment and innovation, technological, structural, and infrastructural. In turn, the determinants through the mechanism of the effect may provide for a different level of economic growth in the AIC, depending on the established conditions. Just like for any other industrial complex, the effect of determinants of the AIC economic growth may bear economic, organizational, institutional, social and other effects. In the context of the management of an economic growth in the AIC, it is important to realize that the conditions of economic dynamics are generated by the agrarian policy with the choice of priorities and mechanisms aimed at the increase of the reproductive nature of the changes in the industry complex based on a balance between economic and social processes.

To ensure a dynamic and sustainable economic growth in the AIC, it is necessary to constantly maintain within the system of management of the processes of agricultural production trends the consistency between the parameters of quantitative, qualitative and reproductive changes in the conditions under the influence of the state branch of the complex factors and determinants of growth conditions which serve both as cause and as consequences. Accordingly, it is necessary to understand to which extent and which parameters determine an economic growth of the AIC taking into account their mutual influence. Therefore, the proposed model of the management of economic growth in the AIC has the parametric content and includes two sets of parameters:

- The dynamic unit determines the quantitative, qualitative and reproductive dynamics of the AIC;

- Within the structural block the impact of factors, conditions, and determinants of economic growth in the AIC is being formed.

The structural and dynamic nature of the system of management of economic growth in the AIC with the appropriate parametric contents determines the stability of growth, flexibility in the use of means and methods of influence on economic processes, as well as a landmark on the results of socio-economic development in view of their importance to agriculture and national economy. According to the conceptual approach, the study of AIC processes of economic growth with structural-dynamic model is built on the following key assumptions:

1. The economic growth in the AIC is determined by quantitative, qualitative and reproduction changes in its condition. Therefore, it is important to determine the effect of each of these components of the economic dynamics on the overall productive performance of the agricultural production. To ensure the objectiveness of the assessment of the nature and strength of its influence, it is advised to input the off correction factors that take into account the specifics of the AIC and its role in the national economic system. 
2. The processes of quantitative, qualitative and reproductive nature of agricultural production are determined by the content and the relation of factors and determinants of economic growth, which in turn are provided by the relevant conditions for the economic dynamics of the AIC as a systematic complex of the national system. Therefore, it is necessary to identify the effect of the influence of factors and determinant of economic growth at the level of the economic parameters of the agricultural production, which are important for the social and economic development of the AIC agricultural sector and the country as a whole.

3. The parameters of the system of management of economic growth in the AIC is based on rank analysis of the structural and dynamic complex of private indicators, depending on the strength and direction of their influence on the processes of economic dynamics.

4. The management of economic growth in the AIC is based on the changes in the parametric content of the economic growth management system based on the priorities of agricultural policy and trends in the business complex.

\section{Results}

The first task in the course of the research was to determine the impact of quantitative, qualitative and reproductive dynamics of the agro-industrial production on the main performance parameters of the agro-industrial complex economic growth. The statistical base was used, which included 147 indicators of the functioning agro-industrial complex of Russia for the period from 2005 till 2014. To perform the correlation analysis, these indicators were differentiated into four groups:

- $\quad \mathrm{X}_{1}$ - quantitative dynamics indicators;

- $\mathrm{X}_{2}$ - qualitative dynamics indicators;

- $\mathrm{X}_{3}$ - reproductive dynamics indicators;

- $\quad \mathrm{Y}$ - Resulting indicators.

Depending on the economic content, each of the indicators was assigned to a group of stimulants or de-stimulants of economic growth. For each group, a complex indicator was calculated as the sum of the normalized values of the partial indices.

The higher growth rates for the analyzed period are typical for the reproductive dynamics (Figure 2). On the whole this has determined the possibility for the economic growth of the agroindustrial complex in modern conditions.

However, in the period from 2010 to 2014 fundamentally changed the ratio of the integrated parameters of the economic dynamics in agriculture. Quantitative dynamics (53\%) exceeded the quality $(46.7 \%)$ and reproductive $(48.5 \%)$ changes in the condition of industrial complex. This situation does not allow forming the basis for the development of the AIC, and poses a threat to the resolution of the agrarian problems in the country.

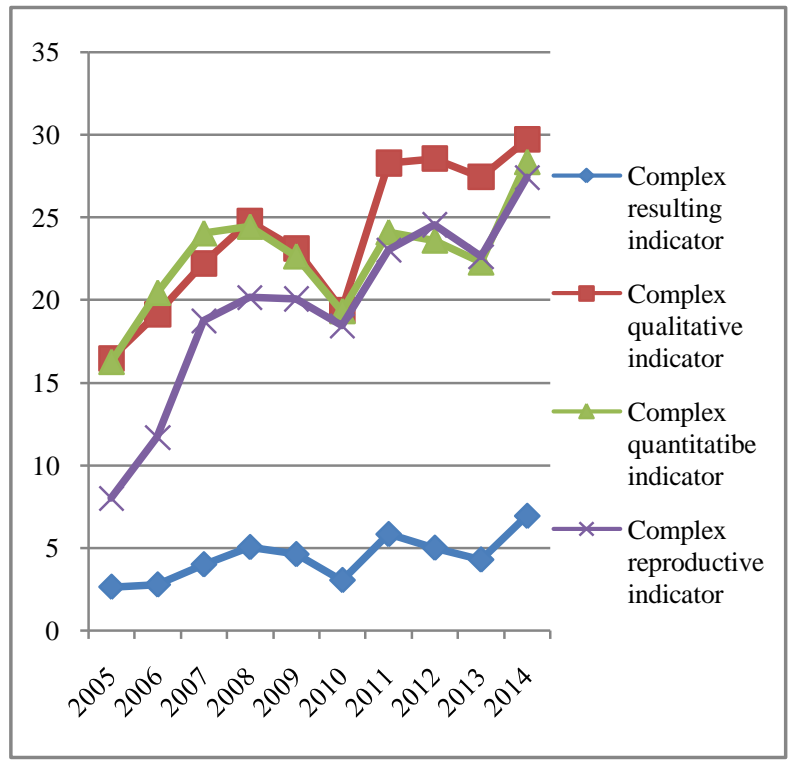

Figure 2 Trends of the complex indicators of the Russian AIC

The resulting regression equation $\mathrm{Y}=-4.01+0.157 \mathrm{X}_{1}+0.221 \mathrm{X}_{2^{-}}$ $0.015 \mathrm{X}_{3}$ showed a positive effect on the overall economic growth of quantitative and qualitative dynamics. The reproductive dynamics adversely affected the resulting parameters of the state of the agro-industrial complex, which is associated with high social costs for this component. In order to correctly assess the impact of quantitative, qualitative and reproductive dynamics on the economic growth of the agro-industrial complex, taking into account the location and importance of agro-industrial production, the coefficients of the national role and social importance of agriculture were introduced in the national economic system. The resulting regression equation $\mathrm{Y}=-3.27+0.029 \mathrm{X}_{1}+0.264 \mathrm{X}_{2}+$ $0.0585 \mathrm{X}_{3}$ showed an increase in the positive influence of qualitative dynamics and a slight positive effect of the reproductive dynamics. However, this ratio of changes in the components of the economic growth of the agro-industrial complex will not allow creating a base for a high and stable dynamics of the industry complex in the long run. The priorities of the current economic policy with regard to the quantitative dynamics of the agro-industrial complex will lead to the transfer of resources from agriculture into the other sectors of the economy without corresponding replenishment and support. 
In order to evaluate the factors, determinants and conditions of the economic growth in the AIC the same approach has been applied at the calculations. In the result of the differentiation of the statistics and assessment the following four groups of indicators have been formed:

- $\quad$ AIC growth factors indicators;

- AIC growth determinants indicators;

- Resulting indicators that determine the conditions and have a high importance for the national economic growth;

- Resulting indicators that determine the conditions and have a high importance for economic growth of the AIC.

- The dynamics of average comprehensive indicators parameter for each group is shown in Figure 3-5.

The main purpose of this part of the study apart from the assessment of the dynamics of complex indicators for each of the group and their correlation has been the assessment of the dynamics of complex indicators for each group and their quantitative analysis was to determine the nature and strength of the influence of factors and determinants of growth on the results of the AIC activity in view of their importance for the economic growth of the national economic system and agricultural production. To this end, four economic and mathematical models have been built, parameters and results of which are presented in Table 1.

\subsection{Key findings of the simulation}

- Among the three integrated indicators included in the model as growth factors, the greatest impact on the level of performance of AIC has been made by the "Labor". Both in the first and in the second model such impact have been negative due to low efficiency of labor resources in the agricultural sector. Thus, there is considerable potential for this group of growth factors;

- $\quad$ The "Capital" factor, included in the growth model, also has the reverse effect with the low level of impact. The main reason is low capitalization parameters of the agricultural production. Ensuring the growing influence of this factor will most certainly contribute to the formation of the potential for

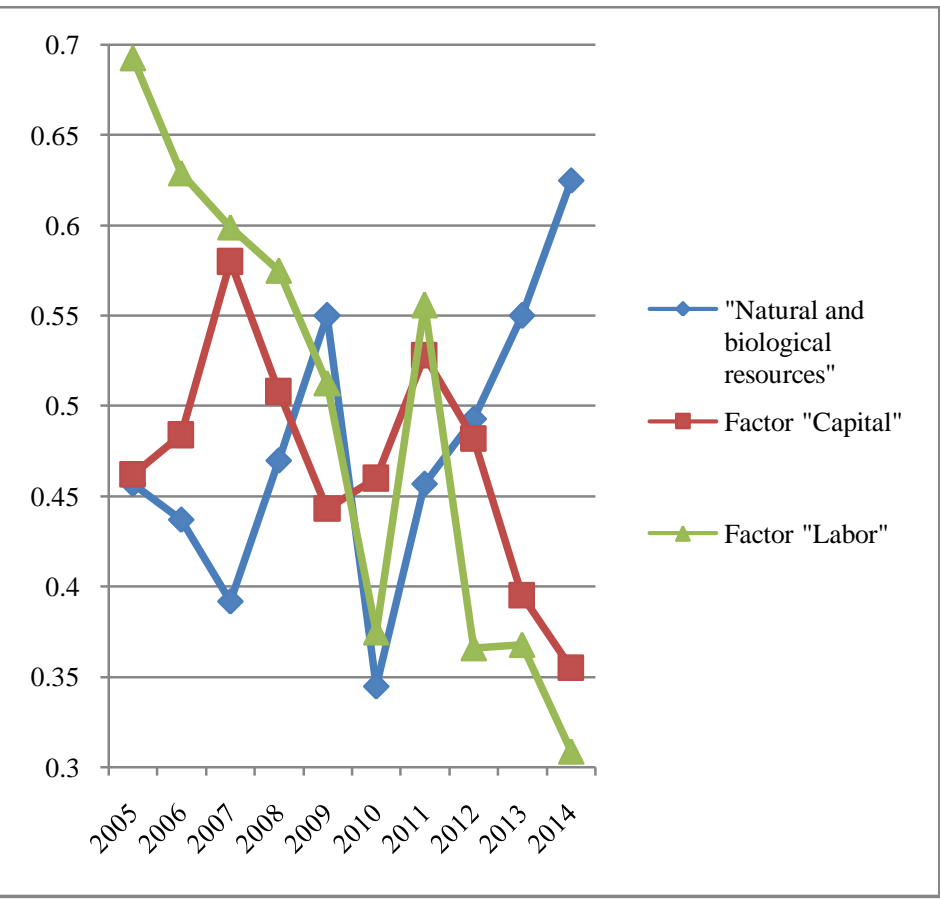

Figure 3 The dynamics of the average comprehensive indicators for sub-factors of the AIC growth

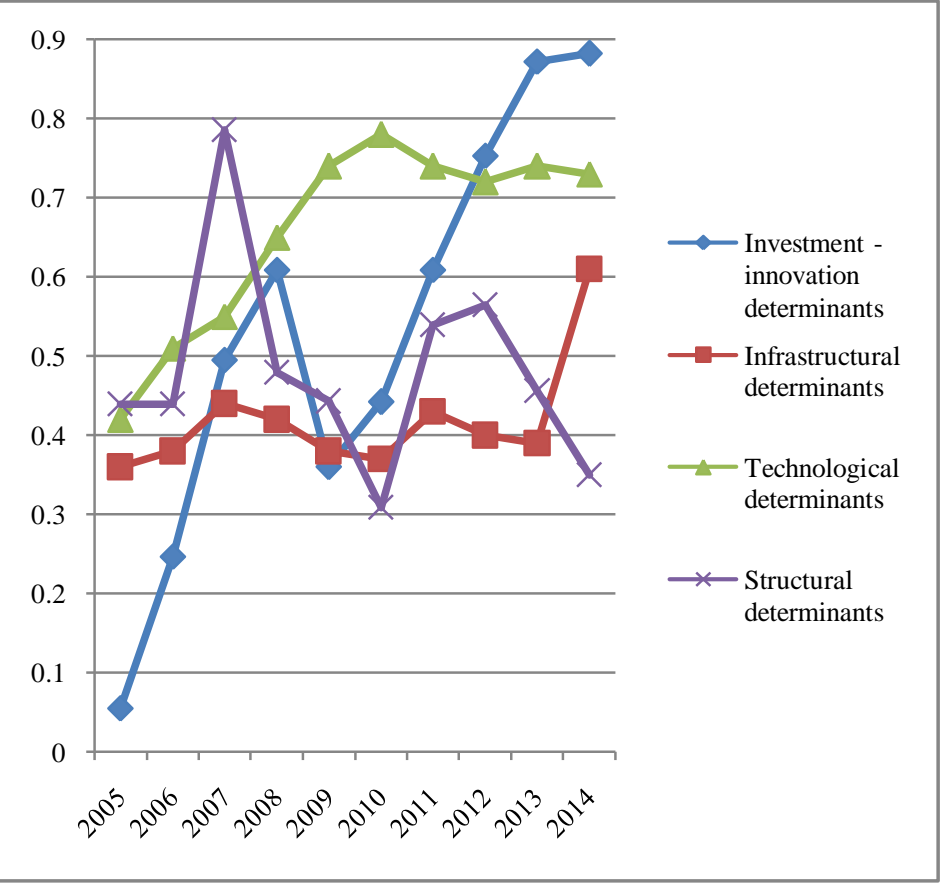

Figure 4 The dynamics of average values of complex parameters for sub-groups of the AIC growth determinants 
economic growth both for the business complex and for the national economic system;

- For the "Natural and biological resources" factor the essential positive impact on the economic dynamics of the industry and national levels has been detected. Considering the objective sufficiency of these factors in the national economic system, the growth potential of

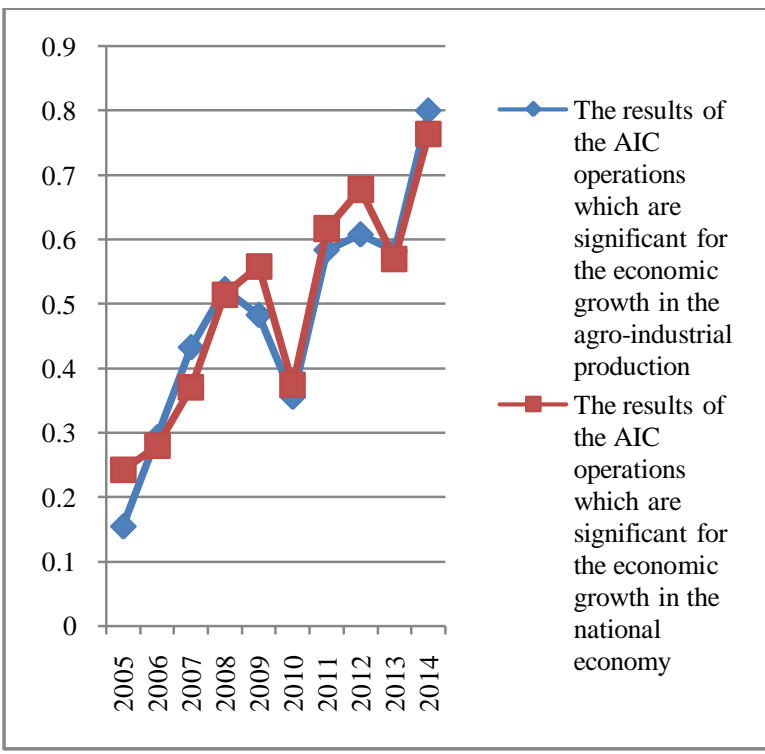

Figure 5 The dynamics of the average comprehensive indicators of the conditions of AIC growth their intensive use should be generated;

- The determinants have a significant impact on the effectiveness of the AIC parameters which are important for the economic growth of the agrarian economy and the national economic system;

- At the formation and use of the AIC economic growth determinants their level and its compliance with the place and role in the industrial complex of the national economic system is not provided;

- The use of the determinants of economic growth in the AIC has unbalanced nature, there is no comprehensive approach to ensure their effect on the economic processes of the industry;

- The most powerful influence on the AIC economic dynamics is made by investments, innovations, and technological determinants. The significant effect of interference of these determinants should be taken into account, which makes it mandatory to enhance the economic growth of the agrarian and the national economy to ensure their integrated use;

- A significant impact of the infrastructure determinants on the resulting parameters of economic dynamics showed why they are important not only for agriculture but also for the economy as a whole. The results of this simulation have revealed the potential of underutilized infrastructure determinants that are most (unlike other

Table 1 The models of dependencies of the AIC performance results on the factors and determinants of economic growth

\begin{tabular}{|c|c|c|}
\hline Model & The resulting figure (y) & Influencing factors $(\mathrm{x})$ \\
\hline 1 & $\begin{array}{l}\text { A comprehensive index of "results AIC activity, } \\
\text { important for the economic growth of agrarian } \\
\text { economy" }\end{array}$ & $\begin{array}{l}\mathrm{X}_{1} \text { - complex index of growth factor "Natural and biological resources"; } \\
\mathrm{X}_{2} \text { - complex index of growth factor "Capital"; } \\
\mathrm{X}_{3} \text { - complex index of growth factor "Labor". }\end{array}$ \\
\hline \multicolumn{3}{|c|}{$Y=-29.652+13.392 X 1+3.087 X 2-6.683 X 3$} \\
\hline 2 & $\begin{array}{l}\text { A comprehensive index of "results AIC activity, } \\
\text { important for the economic growth of the national } \\
\text { economy" }\end{array}$ & $\begin{array}{l}\mathrm{X}_{1} \text { - complex index of growth factor "Natural and biological resources"; } \\
\mathrm{X}_{2} \text { - complex index of growth factor "Capital"; } \\
\mathrm{X}_{3} \text { - complex index of growth factor "Labor". }\end{array}$ \\
\hline \multicolumn{3}{|c|}{$Y=-21.341+8.658 X 1+2.007 X 2-3.719 X 3$} \\
\hline 3 & $\begin{array}{l}\text { A comprehensive index of "results AIC activity, } \\
\text { important for the economic growth of agrarian } \\
\text { economy" }\end{array}$ & $\begin{array}{l}\mathrm{X}_{1} \text { - comprehensive indicator of investment - innovation determinants; } \\
\mathrm{X}_{2} \text { - complex index of infrastructural determinants; } \\
\mathrm{X}_{3} \text { - complex index of technological determinants; } \\
\mathrm{X}_{4} \text { - complex index of structural determinants. }\end{array}$ \\
\hline \multicolumn{3}{|c|}{$Y=-19.169+12.787 X 1+39.685 X 2+18.839 X 3+5.61 X 4$} \\
\hline 4 & $\begin{array}{l}\text { A comprehensive index of "results AIC activity, } \\
\text { important for the economic growth of the national } \\
\text { economy" }\end{array}$ & $\begin{array}{l}\mathrm{X}_{1} \text { - comprehensive indicator of investment - innovation determinants; } \\
\mathrm{X}_{2} \text { - complex index of infrastructural determinants; } \\
\mathrm{X}_{3} \text { - complex index of technological determinants; } \\
\mathrm{X}_{4} \text { - complex index of structural determinants. }\end{array}$ \\
\hline$Y=-9$ & $3 \mathrm{X} 1+17.666 \mathrm{X} 2+14.653 \times 3+1.793 \times 4$ & \\
\hline
\end{tabular}

Journal of Experimental Biology and Agriculture Science http://www.jebas.org 
determinants) able to ensure the sustainability of economic growth in the AIC and to create the conditions for its new quality;

- The significant potential for the economic growth of the AIC lies in its structural determinants. Their weak and negative impact means that there are serious structural problems both in the agricultural and in the national economy, and it clearly demonstrates "gaps" in the existing structural policies;

- The high values of multiple correlation coefficients and determination coefficients indicate the significant influence of a combination of factors and determinants of growth on the resulting indicators of economic dynamics, which involves the use of an integrated approach in their formulation and application.

To determine the parametric content of the AIC economic growth system, the analysis of indicators of structural and dynamic blocks has been carried out, in the result of which the three groups of parameters depending on the strength and nature of their influence on the processes of economic dynamics in agricultural production have been identified.

Group 1: the parameters that have the biggest effect on the economic growth of the AIC. The "two lower quartile rank number" metrics has been selected for identification. These parameters in their content correspond to the priorities of the current economic growth of the AIC. The parameters have been identified which have demonstrated the negative trends in their condition. These parameters should be considered as the main limitations for the economic growth of the AIC. First of all they include a significant increase in accounts receivable and payable, decrease of cattle, reduction in the number of existing and construction of new educational institutions in rural areas, a significant disparity in the prices of exchange and trade relations between the participants of the agrarian market. The low growth of labor productivity with a significant influence of this parameter on the indicators of economic growth of the AIC should also be noted.

Group 2: parameters whose influence on the process of the AIC economic dynamics has been found weak. The "third quartile" metrics has been selected for their identification. In the existing system of the AIC economic growth management the use of this group of parameters was limited. In order to enhance the economic dynamics of the AIC, the parametric content of the system can be supplemented with the appropriate parameters. These parameters should include the average monthly nominal wage in agriculture and its correlation with the Russian average salary level, the factor of wear and coefficient of renewal of fixed assets, the commissioning of facilities for the processing of the major types of agricultural products, the volume of investments in fixed assets, mineral fertilizers, minimizing the price disparity, improvement of the housing.

Group 3: parameters, the effect of which on the economic growth of the AIC has been virtually absent. The "fourth quartile" metrics has been selected for their identification. These parameters can be considered as a major underutilized potential for economic growth of the AIC. The average number of people employed in agriculture and their share in total employment of the economy, the level of energy supply of agricultural production, the volume of budget funds per 1 hectare of sown areas, the scale of reclamation works, the length of paved roads, the number and the construction of additional pre-school educational institutions did not stimulate the economic growth in the AIC.

It should be noted that the general improvement of the situation in the agricultural sector to sustain its dynamism and economic growth is unlikely to be possible. It is quite problematic to discuss the agro-exporting potential of the country. This statement is based on the forecast data obtained using the parameters of the economic growth management system within the current agrarian policy. Until 2020, agriculture will grow by an average annual rate of $2.6 \%$, the processing industry will also grow by $2.7 \%$.

The need for a conceptual restructuring of the AIC economic growth management system becomes so obvious. Classical management principles indicate that the process of economic growth in the AIC should be divided into stages. The content of the stages can be measured as a function of the selected priorities in agricultural policy, the common targets in the national system of management and availability of relevant resources. The current economic situation in Russia in connection with the international sanctions demonstrates the need of dynamic development of domestic agriculture. Therefore, a high level of dynamics can be achieved through formation of a base of reproduction (phase I) and achievement of a fundamentally new quality of growth the AIC (phase II). The analysis of the dynamics, nature and strength of the impact of selected parameters on the economic growth of agribusiness allowed forming strategic initiatives, the implementation of which at each stage will help achieve the objectives (see Figure 6).

In the first phase (2017-2020) it is necessary to achieve selfsufficiency with the general foodstuffs, to maintain the way of life in rural areas, to minimize disparities in structural and sectorial balance.

The management of the economic growth in the AIC at phase II (2020-2025) should be associated with the development of agriculture as the backbone industry of national economy. Russia 


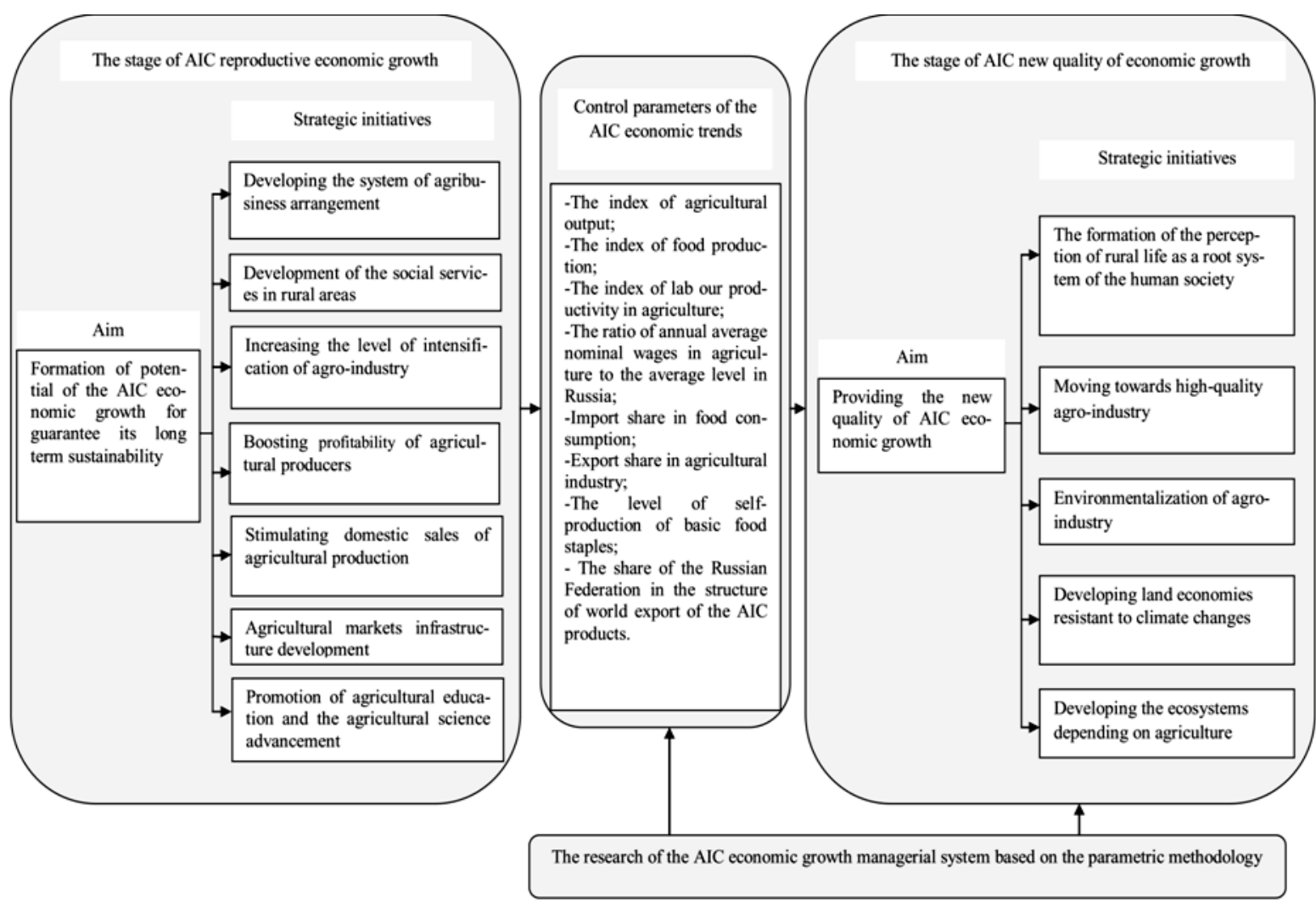

Figure 6. Strategic initiatives in the management of the AIC economic growth

should become a major exporter of food with high added value. At this stage, it is expected to complete the transition to a new paradigm of production, based on advanced manufacturing, information and communication technologies; creating an attractive image of the industry as complex spheres of life; development of scientific and educational model, providing demand for knowledge as a means to hold significant positions in the world food markets.

In order to justify the expediency of changing the agrarian policy and the need to implement the developed strategic alternatives in the field of managing the economic growth of the agro-industrial complex, a forecast model was constructed with the following predicted parameters:

- $\quad \mathrm{Y}_{1}$ - index of agricultural production in the farms of all categories (in comparable prices) by 2015 ;

- $\mathrm{Y}_{2}$ - index of production of food products and beverages (in comparable prices) in 2015;

- $\quad \mathrm{Y}_{3}$ - Labor productivity index (2015).
The values of the indices of the agricultural production and labor productivity were determined depending on the following macroeconomic indicators:

- $\quad \mathrm{X}_{1}$ - share of imports in food consumption;

- $\quad \mathrm{X}_{2}$ - share of exports in agricultural production;

- $\mathrm{X}_{3}$ - Russian share in the world exports of agricultural products.

The index of food production, including beverages (in comparable prices) by 2015 is derived from the index of agricultural production and the labor productivity index. The resulting regression equation $\mathrm{Y}_{2}=5.74+0.557 \mathrm{Y}_{3}+0.386 \mathrm{Y}_{1}$ indicates the quality of the model in terms of proximity and adequacy.

The predicted values of the parameters of the condition of the agro-industrial complex taking into account the changes in the management of economic growth (Table 2) indicate the possibility of achieving high dynamics of agro-industrial production in Russia and strengthening the country's position in the world food market. 
Table 2 The indicators of the implementation of strategic initiatives to manage the economic growth of the AIC

\begin{tabular}{|c|c|c|c|c|c|}
\hline Indicator & 2015 & $2016 *$ & 2020 & $\begin{array}{l}\text { PhaseI } \\
2020\end{array}$ & $\begin{array}{l}\text { PhaseII } \\
2025\end{array}$ \\
\hline $\begin{array}{l}\text { The index of agricultural production in all categories of farms (in } \\
\text { comparable prices), compared to the year } 2015(\%) \text {. }\end{array}$ & 103.0 & 104.8 & $109.75^{* *}$ & 131.1 & 190.3 \\
\hline $\begin{array}{l}\text { The index of food production, including beverages(in comparable } \\
\text { prices)compared to the year } 2015(\%)\end{array}$ & 102.2 & 102.6 & $120.5^{* *}$ & 134.5 & 198.8 \\
\hline The index of labor productivity (compared to the year 2015) (\%) & 103.8 & 104.3 & $119.3^{* *}$ & 140.0 & 214.3 \\
\hline $\begin{array}{l}\text { The ratio of nominal wages in agriculture to the average level in } \\
\text { Russia, \%. }\end{array}$ & 57.9 & 65.6 & - & 80.0 & 100.0 \\
\hline \multicolumn{6}{|l|}{ Level of self-production of basic food staples (\%) } \\
\hline Grain & 99.2 & 99.2 & $95^{* * *}$ & 100 & 100 \\
\hline Milk and milk products (in milk equivalent) & 81.2 & $81.5-$ & $90 * * *$ & 90 & 100 \\
\hline Meat and meat products (in meat equivalent) & 87.4 & 89.7 & $85^{* * * *}$ & 95 & 100 \\
\hline Sugar & 83.5 & 88.7 & $80 * * *$ & 95 & 100 \\
\hline Seedoil & 83.9 & 83.6 & $80 * * *$ & 95 & 100 \\
\hline Potato & 97.4 & 97.7 & $95^{* * *}$ & 100 & 100 \\
\hline Import share in food consumption. & 0.31 & - & - & 0.15 & 0.08 \\
\hline Export share in agricultural industry. & 0.16 & - & - & 0.2 & 0.3 \\
\hline $\begin{array}{l}\text { The share of Russia in the structure of world export of agro-industry } \\
\text { products. }\end{array}$ & 1.3 & - & - & 2.6 & 3.9 \\
\hline
\end{tabular}

\section{Discussion and Conclusion}

The agrarian sector of Russia in modern conditions demonstrates the positive trends. According to the Federal State Statistics Service, the growth in agricultural production (in comparable prices) in 2016 constituted $104.8 \%$, the profitability of agricultural companies (including subsidies) reached $17.3 \%$, the labor productivity index increased by $4.3 \%$ compared to a year earlier. The agricultural sector in the main economic indicators took the leading position among other types of economic activity, positively affecting the dynamics of GDP. However, the modern agrarian policy has a more tactical character, which is determined by a rather persistent orientation toward gross production (the quantitative growth), instead of ensuring economic accessibility of the high-quality food (the qualitative growth), the formation of progressive material resources and farms with technological capacities (the reproductive growth). As it has been shown by this study, such a situation cannot ensure a high and stable dynamics of agro-industrial production in the country and will inevitably lead to specific strategic problems in the field of food and national security.

The progress in agricultural production and its social sphere based on the management of the AIC economic growth is a component of civilized market relations with the state regulation mechanism. It is not just the global economic national economic problem. It requires adequate political will by the supreme power and the activities of legal and administrative implementation of such will by the well-developed mechanism.

\section{Conflict of Interest}

Authors would hereby like to declare that there is no conflict of interests that could possibly arise.

\section{References}

Akayev AA, Korotaev AV, Malinetskiy GG, Malkov SY (2012) Modeling and Forecasting of Global, Regional and National Development. Knizhnyy dom LIBROKOM, Moscow. 
Anokhina MY (2016) The structural limitations of economic growth of the AIC. International Journal of Applied and Fundamental Research 4-6: 1126-1135.

Arrow KJ (1962) The Economic Implications of Learning by Doing. Review of Economic Studies 29:155-173.

Ayres RU (2006) Did the Fifth K-Wave Begin in 1990-92? Has it been Aborted by Globalization? Kondratieff Waves, Warfare and World Security. IOS Press, Amsterdam: 57-71.

Bain JS (1959) Industrial organization. John Wiley \& Sons, New York.

Barro R (1997) Determinants of Economic Growth: a CrossCountry Empirical Study. Harvard Institute for International Development Discussion Paper 579.

Barro R, Lee J (1994) Sources of Economic Growth (with comments from Nancy Stokey). Carnegie-Rochester Conference Series on Public Policy 40: 1-57.

Baumol WJ, Panzar JC, Willing RD (1982) Contestable markets and the theory of industry structure. Harcourt Brace Jovanovich, New York.

Bodrunov SD (2013) Formation of the Strategy of Reindustrialization of Russia. Institute for New Industrial Development (INIR), St. Petersburg.

Buzgalin AV (2014) The Economic System of Russia: Anatomy of the Present and the Strategy of the Future (Reindustrialization and/or Rapid Development). LENAND, Moscow.

Cass D (1965) Optimum Growth in an Aggregative Model of Capital Accumulation. Review of Economic Studies 32:233-240.

Demsetz H (1974) Two systems of belief about monopoly. Industrial Concentration. The New Learning, Boston: 164-184.

Denison EF (1967) Why Growth Rates Differ: postwar experience in nine different countries. D.C.: Brookings Institution, Washington.

Diamond P (1965) National Dept in a Neoclassical Growth Model. American Economic Review 55:1126-1150.

Domar E (1957) Essays in the Theory of Economic Growth. Oxford University Press.

Fisher I (1933) The Debt Deflation Theory of Great Depressions. Econometrica $1: 337-357$.

Forrester J (2006) World Dynamics. AST, Moscow.
Freeman C (1982) The Economics of Industrial Innovation. Frances Pinter, London.

Freeman C, Louca F (2001) As Time Goes By: From the Industrial Revolutions to the Information Revolution. Oxford University Press Inc, Oxford.

Glazyev SY, Fetisov GG (2013) On the Strategy for Sustainable Economic Development. The Economist 1: 3-31.

Grubler A (1998) Technology and Global Change. Cambridge University Press, Cambridge, UK.

Gubanov S (2012) A Breakthroughof the Power. Neoindustrialization of Russia Plus Vertical Integration. Knizhnyy mir, Moscow.

Hamberg D (1971) Models of Economic Growth. Harper and Row, New York.

Hansen AH (1951) Business cycles and national income . Norton, New York.

Harrod RF (1973) Economic Dynamics. Macmillan, London.

Heather K (2004) The Economics of Industries and Firms:In Russian. Finance and statistics, Moscow.

Hicks J (1992) The Mainspring of Economic Growth, Nobel Lectures, Economics 1969-1980,

Hirooka M (2006) Innovation Dynamism and Economic Growth. A Nonlinear Perspective. Northampton, MA: Edwards, Cheltenham, UK.

Koopmans T (1965) On the Concept of Optimal Economic Growth. Pontificiae Academiae Scientiarum Scripta Varia 28, 1, Semaine D'Etude sur Le Role de L'analyse Econometrigue dans la Formulation de Plans de Developpent.

Krasilnikov OY (2005) Problems of Structural Adjustment in the Economy. The Economist 8: 52-58.

Levine R, Renelt D (1992) A Sensitivity Analysis of CrossCountry Growth Regressions. American Economic Review 824:942-963.

Mason ES (1949) The Current State of the Monopoly Problem in the United States. Harvard Law Review 62:1265-1285.

Nelson RR, Winter SG (2002) An Evolutionary Theory of Economic Change. Delo, Moscow. 
Phelps ES (1962) The new view of investment: A neoclassical analysis. Quarterly Journal of Economics 76 :548-567.

Piketty T (2016) Capital in the Twenty-First. Ad Marginem, Moscow.

Ramsey FP (1928) A Mathematical Theory of Saving. Economic Journal 38:543-559.

Robinson J (1962) Essays in the Theory of Economic Growth. Macmillan, London.

Romer P (1993) Idea Gaps and Object Gaps in Economic Development. Journal of Monetary Economics 32-3:543-573.

Rostow WW (1980) Why the Poor Get Richer and the Rich Slow Down: Essays in the Marshallian Long Period. University of Texas Press, Austin.

Scherer FM, Ross D (1990) Industrial Market Structure and Economic Performance. Houghton Mifflin, Boston.
Shell K Ed. (1967) Essays on the Theory of Optimal Economic Growth. Massachusetts: MIT Press , Cambridge:67-85.

Solow RM (1956) A Contribution to the Theory of Economic Growth. Quarterly Journal of Economics 70:65-94.

Sukharev OS, Logvinov SA (2013) Management of Structural Changes in the Economy. INFRA-M, Moscow.

Uzawa H (1963) On a Two-Sector Model of Economic Growth II. Review of Economic Studies 30:105-118.

Viscusi WK, Vernon JM, Harrington JE (2000) Economics of regulation and antitrust. Mass. : MIT Press, Cambridge.

Voronin YM , Seleznev AZ, Cherednichenko LG (2004) Russia: Economic Growth. Financial control - Publishing house, Moscow.

Yakovets YV(2004) Epoch-making Innovations of the XXI Century. Economy, Moscow. 